\title{
Free Testosterone to Total Protein Ratio Measurement
}

National Cancer Institute

\section{Source}

National Cancer Institute. Free Testosterone to Total Protein Ratio Measurement. NCI

Thesaurus. Code C128980.

The determination of the ratio of free testosterone compared to total protein present in a sample. The measurement may be expressed as a ratio or percentage. 